\title{
Long-term maintenance of immediate or delayed extinction is determined by the extinction-test interval
}

\author{
Justin S. Johnson, Martha Escobar, ${ }^{1}$ and Whitney L. Kimble \\ Department of Psychology, Auburn University, Auburn, Alabama 36849, USA
}

\begin{abstract}
Short acquisition-extinction intervals (immediate extinction) can lead to either more or less spontaneous recovery than long acquisition-extinction intervals (delayed extinction). Using rat subjects, we observed less spontaneous recovery following immediate than delayed extinction (Experiment 1). However, this was the case only if a relatively long extinction-test interval was used; a relatively short extinction-test interval yielded the opposite result (Experiment 2). Previous data appear consistent with this observation suggesting that, although delayed extinction appears more beneficial in the short term, immediate extinction may have more favorable long-term effects. These observations may have important implications for attenuation of relapse in clinical situations.
\end{abstract}

Extinction refers to attenuated conditioned responding following presentations of a conditioned stimulus (CS) in the absence of its unconditioned stimulus (US; i.e., CS-US then CS-). Although extinction has sometimes been described as a form of unlearning (e.g., Rescorla and Wagner 1972), it likely reflects learning of a new association during the CS-alone trials (e.g., CS-no US) (Bouton 1993). Extinguished behavior is known to spontaneously recover some time after extinction (Pavlov 1927; Rescorla 2004a), although under certain conditions it may become resistant to spontaneous recovery (SR). For example, Lin et al. $(2003 a, b)$ reported that synaptic depotentiation (which opposes long-term potentiation [LTP] at most levels) induced less than $1 \mathrm{~h}$ after LTP attenuated subsequent expression of conditioned fear. Myers et al. (2006) reasoned that extinction conducted shortly after acquisition should benefit from such depotentiation process and exhibit attenuated relapse. Indeed, they observed that immediate extinction was more resistant to SR than delayed extinction. Nonetheless, other researchers have failed to observe such a benefit of immediate extinction (Rescorla 2004b; Maren and Chang 2006; Norrholm et al. 2008; Schiller et al. 2008; Woods and Bouton 2008; Chang and Maren 2009).

The present studies investigated the relationship between the acquisition-extinction interval and SR from extinction. The subjects were 144 experimentally naïve male Sprague-Dawley rats (Experiment 1: 64, Experiment 2: 80), approximately $60 \mathrm{~d}$ old at initiation of the studies. Subjects were pair-housed in standard plastic cages on a 12:12-h light:dark cycle. Water availability was restricted to $30 \mathrm{~min} / \mathrm{d}$ (food was available ad libitum).

The apparatus was eight identical chambers $(30.5 \times 24.1 \times$ $21.0 \mathrm{~cm}$ ). Each chamber was housed in a melamine soundattenuation cubicle illuminated with a 100-mA houselight delivered at $28 \mathrm{VDC}$, and equipped with an exhaust fan that provided a constant, $70 \mathrm{~dB}(\mathrm{~A})$, background noise. The sidewalls of the chamber were made of aluminum sheet metal, and the remaining walls and ceiling were made of clear polycarbonate. The floor consisted of $4.8 \mathrm{~mm}$ stainless-steel rods, spaced $1.6 \mathrm{~cm}$ centerto-center, which could be electrified with a scrambled footshock. All chambers had two speakers that delivered a 60 -sec white noise pulsating two times/sec or $60-\mathrm{sec} 4000-\mathrm{Hz}$ tone, both at $80 \mathrm{~dB}(\mathrm{~A})$. These stimuli served as X and A (counterbalanced). Depressing a

'Corresponding author.

E-mail escobmc@auburn.edu; fax (334) 844-4447.

Article is online at http://www.learnmem.org/cgi/doi/10.1101/lm.1932310. response lever (protracted on a side wall) was associated with delivery of $0.05-\mathrm{mL}$ droplets of water reinforcement into a cup located inside a $5.1 \times 5.1 \times 5.1 \mathrm{~cm}$ niche, $1.5 \mathrm{~cm}$ above the grid floor.

Experiment 1 was conducted in two replications, in one of which half of the boxes had a polycarbonate plate placed on a $41^{\circ}$ angle inside the chamber, reducing its bottom to $17.1 \mathrm{~cm}$ in length without occluding the lever, houselight, or speakers. All polycarbonate walls were covered with a checkerboard pattern. Chamber type was irrelevant to the present studies. Neither chamber type nor replication had any statistical effects; thus, all data were pooled across these factors.

Lever-pressing was trained in four 1-h autoshaping sessions, during which reinforcement was delivered on concurrent FT5-min/FR-1 (Day 1), FR-1 (Days 2 and 3), and VI-20-s (Day 4 and remainder of the study) schedules. On Day 5 (Delayed condition) or Day 6 (Immediate condition), all subjects received three pairings of CS X and the $0.85-\mathrm{mA}$ footshock US, which occurred at 2,12 , and $22 \mathrm{~min}$ after placement in the test chambers. Two minutes after the third conditioning trial, all animals were removed from the testing chambers and returned to their home cages. Subjects were then returned to the testing chambers for the extinction phase. The total time elapsed between the last conditioning trial and the first extinction trial was $12 \mathrm{~min}$ (Immediate condition) or $24 \mathrm{~h}$ (Delayed condition). Extinction subjects received 20 presentations of CS X, whereas Control subjects received 20 presentations of CS A (mean intertrial interval: 3 min). Seventy-two hours after completion of extinction, subjects were returned to the testing chambers and received six presentations of CS X, spaced 10 min apart. Further extinction was expected to result from the test exposures after SR (relapse). Consequently, testing was repeated $48 \mathrm{~h}$ later to assess whether the timing (immediate vs. delayed) of initial extinction affected the effectiveness of subsequent extinction after relapse (reextinction would be the natural option in a clinical relapse situation). Note that the training described above equated with the extinction-test interval, but varying the acquisition-extinction interval necessarily varied the acquisition-testing interval. However, behavioral changes resulting from extinction are more sensitive to the passage of time than those resulting from acquisition (e.g., Bouton 1993; Woods and Bouton 2008), and previous research suggests that the acquisition-test interval does not interact with the acquisition-extinction interval (also see Maren and Chang 2006). 
Shock treatment usually disrupts baseline behavior, which precludes the calculation of suppression ratios (see below for elaboration). To improve the baseline during the testing phase, we provided a 1-d restabilization-of-baseline treatment on the day preceding testing. Furthermore, to determine whether baseline disruptions were due to incidental lever-pressing-shock pairings, the levers were not available during acquisition and extinction for half of the subjects in Experiment 1 (they were available during shaping, restabilization, and testing). The number and timing of exposures to the CS and US were equated in the lever and no-lever conditions. Lever availability had no statistical impact on the SR test; thus, all test data were collapsed across this factor.

Data were converted to suppression ratios, using the formula $A /[A+(B / 3)]$, where $A$ represents responding during the 30 -sec CS period and $B$ represents responding during a $90-\mathrm{sec}$ baseline period. All data were analyzed using standard repeated-measures analyses of variance (ANOVA) with a significance level of $P<$ 0.05 . Test data were analyzed in three-trial blocks. The data from five subjects (Groups Extinction-Immediate and ControlDelayed: one subject each; Group Control-Immediate: three subjects) were excluded from the repeated-measures analyses because, for all trials in a block, both the $A$ and $B$ measures were zero and suppression ratios could not be calculated.

A Condition (extinction vs. control) $\times$ Acquisition-Extinction Interval (immediate vs. delayed) $\times$ Test Day $\times$ Block ANOVA revealed the main effects of Condition, Test Day, and Block, $F_{\mathrm{s}_{(1,55)}}=9.01,24.34$, and 67.75, respectively, and a Condition $\times$ Acquisition-Extinction Interval interaction, $F_{(1,55)}=6.71$. CS X elicited less suppression in the Immediate-Extinction than the Immediate-Control group in all blocks across both testing days, with this difference growing larger as the extinction test progressed, $F \mathrm{~s}_{(1,55)}=6.70$ (test) and 11.28 (retest). In contrast, CS X elicited similar levels of suppression in the Delayed-Extinction and Delayed-Control groups in all blocks across both testing days, with re-extinction after SR resulting in little separation among the two groups, $F \mathrm{~s}<0.06$ (see Fig. 1).

Our data are consistent with the report by Myers et al. (2006) that immediate extinction undergoes less SR than delayed extinction. However, our results are inconsistent with other reports that immediate extinction results in equivalent (Norrholm et al. 2008; Schiller et al. 2008) or greater (Rescorla 2004b; Maren and Chang 2006; Woods and Bouton 2008; Chang and Maren 2009) SR than delayed extinction. In order to elucidate the variables that determine these inconsistent reports, we analyzed previous studies that specifically assessed SR after manipulating the acquisition-extinction interval. Table 1 summarizes our analysis. Studies that obtained more SR after immediate than delayed extinction are presented in white cells, and studies that obtained similar or less SR after immediate than delayed extinction are presented in shaded cells. The only variable that appeared to divide these two groups was the extinction-test interval: Studies in the white cells assessed behavior 24$48 \mathrm{~h}$ after extinction, whereas studies in the shaded cells assessed behavior 72 or more hours after extinction.

The two studies obtaining similar levels of SR after immediate and delayed extinction may have been less sensitive to group differences for various reasons. Schiller et al. (2008) (Experiment 3) observed similar levels of SR $21 \mathrm{~d}$ after immediate or delayed extinction. However, this study confounded the acquisition-extinction interval with where subjects spent this interval (extinction context for the immediate condition; home cages for the delayed condition). Norrholm et al. (2008) observed more SR after delayed than immediate extinction, but SR became equivalent in the two conditions after controlling for contextual fear. However, this study equated the acquisition-test interval in the two delay conditions ( $4 \mathrm{~d}$ ), thus confounding the acquisition-extinction (10 min vs. $24 \mathrm{~h}$ ) and extinction-test intervals ( $96 \mathrm{~h}$ vs. $24 \mathrm{~h}$; see Table 1 ).

One study may be problematic for the account described above. Rescorla (2004b, Experiment 4) trained three different stimuli, with acquisition-extinction intervals of 29,15 , or 1 d. After a 7-d retention interval, he observed less SR to the distally trained stimulus than the proximally trained stimuli. However, the immediate interval in Rescorla's studies was as long as the other studies' delayed intervals. Furthermore, in Rescorla's study extinction occurred over multiple days (as opposed to $1 \mathrm{~d}$ in the other studies), and the ensuing longer intertrial intervals may have led to better retention of extinction to the more distal stimulus (Tsao and Craske 2000; Urcelay et al. 2009).

The apparatus, design, and procedure of Experiment 2 were the same as those of Experiment 1, with three exceptions. First, the level of footshock was decreased (from 0.85 to $0.70 \mathrm{~mA}$ ) to better maintain baseline responding during acquisition and testing and observe more moderate levels of SR than those observed in Experiment 1. Second, levers were available for all subjects during acquisition and extinction. Third, the extinction-test interval was manipulated, and SR was assessed either $48 \mathrm{~h}$ (Short interval) or 7 $\mathrm{d}$ (Long interval) after completion of extinction. A second test was given $24 \mathrm{~h}$ later as described in Experiment 1 (see Fig. 2A).

Experiment 2 was conducted in two identical replications. Replication had no statistical effect; thus, all data were collapsed across this factor. Figure 2B presents the data collected during the extinction phase in four-trial blocks. A Condition $\times$ Acquisition-Extinction Interval $\times$ Block ANOVA revealed main effects of Condition, $F_{(1,50)}=19.72$, and Block, $F_{(2,200)}=32.78$, but no effect or interaction with acquisition-extinction interval, $F \mathrm{~s}<1$. A similar analysis conducted on the last block of extinction revealed no effects or interaction, $F$ s $<1.20$. Thus, we failed to observe faster extinction in the immediate than delayed condition as previously reported by others (Maren and Chang 2006; Schiller et al. 2008; Woods and Bouton 2008). Unfortunately,
A

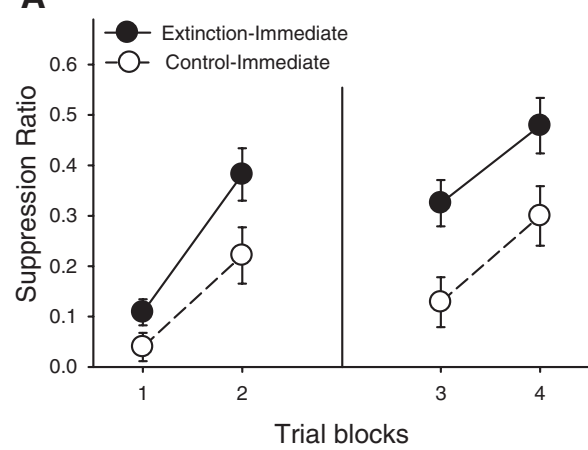

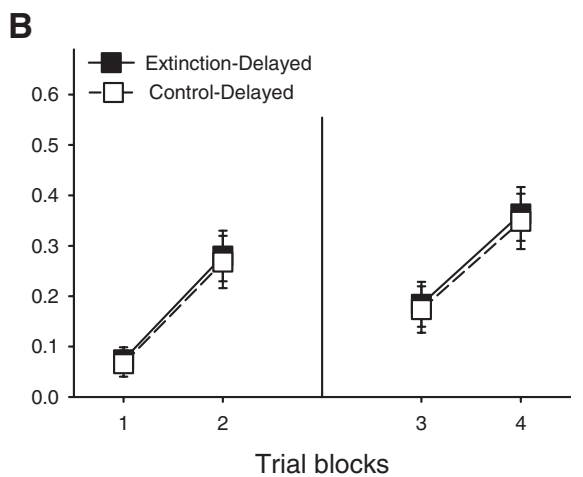

B

Figure 1. Spontaneous recovery test, Experiment 1 (three-trial blocks). $(A)$ Immediate condition (extinction $10 \mathrm{~min}$ after acquisition); $(B)$ delayed condition (extinction $24 \mathrm{~h}$ after acquisition). Extinction subjects received $X$ presentations during the extinction phase, whereas Control subjects received equivalent A presentations; "Immediate" refers to extinction 10 min after acquisition, whereas "Delayed" refers to extinction $24 \mathrm{~h}$ after acquisition. Trial blocks 1 and 2 present the data collected during the first test, which occurred $72 \mathrm{~h}$ after extinction; trial blocks 3 and 4 present the data collected during the re-test, which occurred $48 \mathrm{~h}$ later. Brackets represent SEMs. 
Table 1. Comparison of previous studies investigating the acquisition-extinction interval

\begin{tabular}{|c|c|c|c|c|c|c|c|c|c|c|}
\hline \multirow[b]{2}{*}{ Study } & \multirow[b]{2}{*}{ Species } & \multirow[b]{2}{*}{ Measure } & \multirow[b]{2}{*}{ CS } & \multirow[b]{2}{*}{ US } & \multicolumn{2}{|c|}{ Trial \# $\#^{a}$} & \multicolumn{2}{|r|}{$\mid \mathrm{ITI}^{\mathrm{b}}$} & \multicolumn{2}{|c|}{ Interval } \\
\hline & & & & & Acq. & Ext. & Acq. & Ext. & Acq.-Ext. ${ }^{c}$ & Ext.-Test \\
\hline Rescorla (2004b) ${ }^{d}$ & $\begin{array}{l}\text { Rat } \\
\text { Pigeon }\end{array}$ & $\begin{array}{l}\text { Head entries; Chain pull } \\
\text { Keypecks }\end{array}$ & $\begin{array}{l}\text { Auditory Visual } \\
\text { Visual }\end{array}$ & $\begin{array}{l}\text { Food } \\
\text { Food }\end{array}$ & $\begin{aligned} & 32 ; 128 \\
& 120\end{aligned}$ & $\begin{array}{l}12 \\
16\end{array}$ & $\begin{array}{l}2.5 \mathrm{~min} \\
2.5 \mathrm{~min}\end{array}$ & $\begin{array}{l}2.5 \mathrm{~min} \\
2.5 \mathrm{~min}\end{array}$ & $\begin{array}{l}24 \text { h vs. } 9 \text { d } \\
9 \text { d vs. } 29 \text { d }\end{array}$ & $\begin{array}{l}48 \mathrm{~h} \\
7 \mathrm{~d}\end{array}$ \\
\hline Myers et al. (2006) & Rat & Fear potentiated startle & Visual & Shock & 15 & 90 & $2 \min$ & $5 \mathrm{~min}$ & $\begin{array}{l}10 \text { min vs. } 1 \mathrm{~h} \text { vs. } \\
72 \mathrm{~h}\end{array}$ & $21 \mathrm{~d}$ \\
\hline Maren and Chang (2006) & Rat & Conditioned freezing & Auditory & Shock & $5 ; 1$ & $45 ; 225$ & $62 \mathrm{sec}$ & 60 or $12 \mathrm{sec}$ & 15 min vs. 24 h & $\begin{array}{l}48 \mathrm{~h} \text { from acquisition or } \\
48 \mathrm{~h} \text { from extinction }\end{array}$ \\
\hline Norrholm et al. (2008) & Humans & $\begin{array}{l}\text { Startle response } \\
\text { (eyeblink) }\end{array}$ & Auditory Visual & $\begin{array}{l}\text { Air puff to } \\
\text { larynx }\end{array}$ & 8 & 16 & $15.5 \mathrm{sec}$ & $15.5 \mathrm{sec}$ & $10 \mathrm{~min}$ vs. $72 \mathrm{~h}$ & $\begin{array}{l}96 \mathrm{~h} \text { for immediate } \\
\text { condition, } 24 \mathrm{~h} \text { for } \\
\text { delayed condition }\end{array}$ \\
\hline Schiller et al. (2008) & Rat & Conditioned freezing & Auditory & Shock & 12 & 16 & $5 \mathrm{~min}$ & $2 \min$ & $12 \mathrm{~min}$ vs. $72 \mathrm{~h}$ & $21 \mathrm{~d}$ \\
\hline \multirow[t]{2}{*}{ Woods and Bouton (2008) } & Rat & $\begin{array}{l}\text { Conditioned emotional } \\
\text { response }\end{array}$ & & Shock & 4 & $16 ; 32$ & $20 \mathrm{~min}$ & 2.7 or $6.5 \mathrm{~min}$ & $10 \mathrm{~min}$ vs. $24 \mathrm{~h}$ & $24 \mathrm{~h}$ \\
\hline & & Head entries & Auditory & Food & 40 & 20 & $2.08 \mathrm{~min}$ & $2.08 \mathrm{~min}$ & & \\
\hline Chang and Maren (2009) & Rat & Conditioned freezing & Auditory & Shock & 5 & 45 & $60 \mathrm{sec}$ & $\mathrm{N} / \mathrm{A}$ & $\begin{array}{l}15 \text { min vs. } 1 \text { h vs. } \\
6 \mathrm{~h} \text { vs. } 24 \mathrm{~h}\end{array}$ & $\begin{array}{l}48 \mathrm{~h} \text { for animals with } \\
\text { acq.-ext. intervals of } \\
\text { less than } 24 \mathrm{~h}, 24 \mathrm{~h} \text { for } \\
\text { the rest }\end{array}$ \\
\hline Experiment 1 & Rat & $\begin{array}{l}\text { Conditioned emotional } \\
\text { response }\end{array}$ & Auditory & Shock & 3 & 20 & $10 \mathrm{~min}$ & $3 \mathrm{~min}$ & $12 \mathrm{~min}$ vs. $24 \mathrm{~h}$ & $72 \mathrm{~h}$ from extinction \\
\hline
\end{tabular}

Note: CS, conditioned stimulus; US, unconditioned stimulus; Acq., acquisition (CS-US trials); and Ext., extinction (CS-no US presentations).

${ }^{a}$ Numbers separated by a semicolon represent various trial numbers used in the different studies (not a parametric manipulation).

${ }^{\mathrm{b}}$ Random or variable ITIs are presented with their mean value.

'For training that occurred over multiple days, the interval was measured from the last day of conditioning.

'There was one more study in this paper, which extinguished the operant response of lever-pressing, but those parameters were not included in the table (only CS-driven responses were considered).

eThere was a human study in this paper, which yielded spontaneous recovery after immediate (12 sec) extinction, but this was the only acq.-ext. interval assessed in the paper. Shaded cells highlight experiments

in which spontaneous recovery was observed to be equivalent independent of acquisition-extinction interval or greater with a longer interval (delayed condition) than a shorter interval (immediate condition). 
A

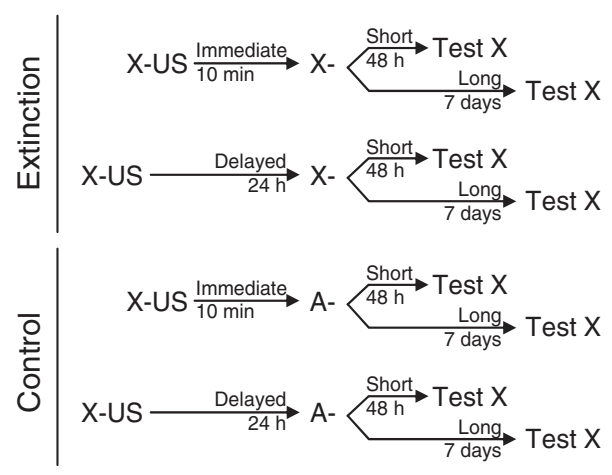

B

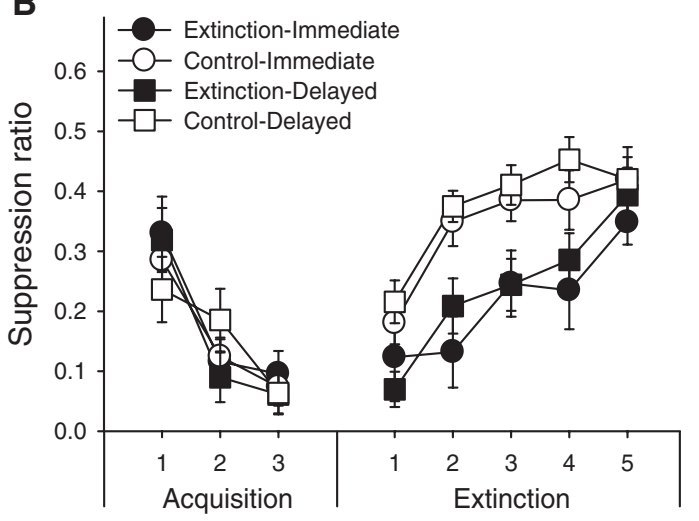

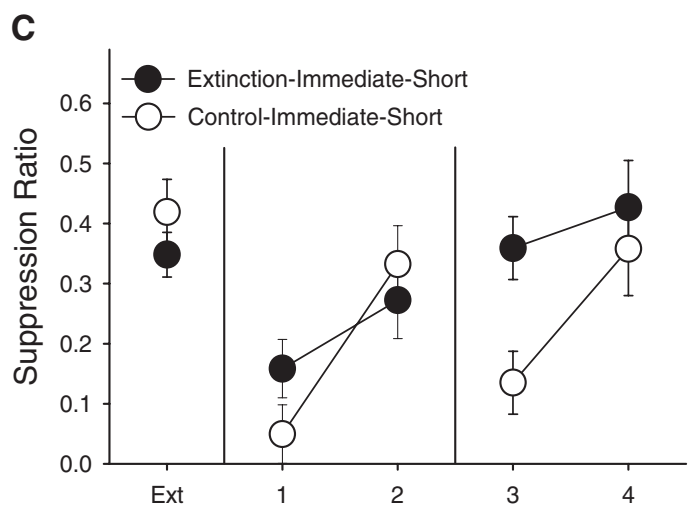

E

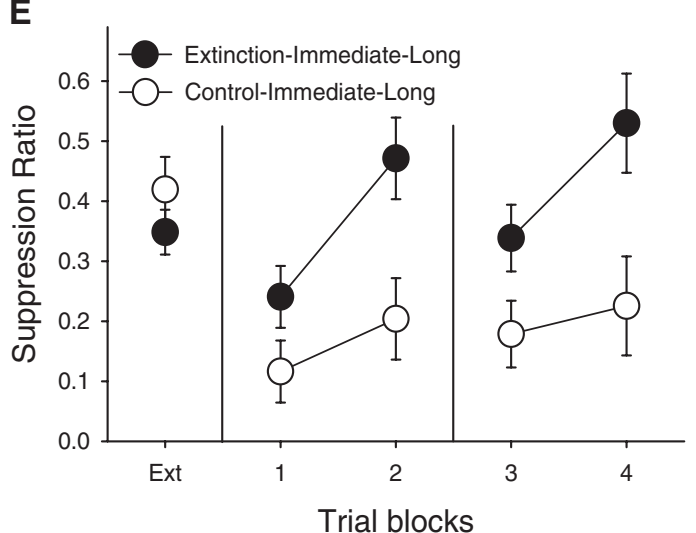

D

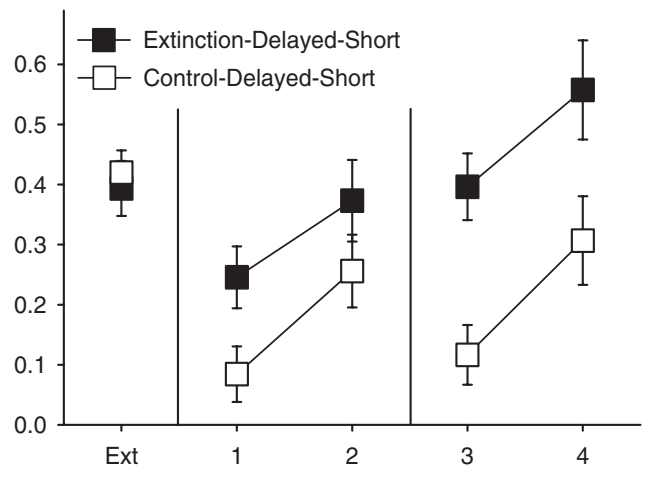

$\mathbf{F}$

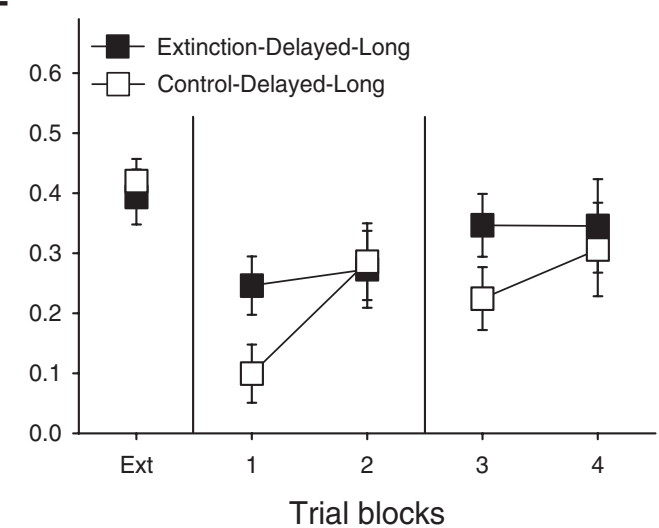

Figure 2. (A) Training protocol, Experiment 2. (B) Acquisition and extinction data (four-trial blocks). (C-F) Spontaneous recovery test, Experiment 2 (three-trial blocks). Each Extinction group is presented in juxtaposition to its Control group. (C) Immediate-Short condition; $(D)$ Delayed-Short condition; $(E)$ Immediate-Long condition; and $(F)$ Delayed-Long condition. In all panels, Extinction subjects received X presentations during the extinction phase, whereas Control subjects received equivalent A presentations; "Immediate" refers to extinction 10 min after acquisition, whereas "Delayed" refers to extinction $24 \mathrm{~h}$ after acquisition; and "Short" refers to testing $48 \mathrm{~h}$ after extinction, whereas "Long" refers to testing $7 \mathrm{~d}$ after extinction. In panels $C$ and $D$, Ext presents responding during the last block of extinction as displayed in panel $B$, trial blocks 1 and 2 present the data collected during the first test (at the Short or Long Interval), and trial blocks 3 and 4 present the data collected during the retest ( $48 \mathrm{~h}$ later). Brackets represent SEMs.

baseline disruptions significantly reduced the number of subjects entering the repeated-measures analyses. Missing scores were replaced with group means, but if more than two scores were missing, the subject was excluded from the analysis. Of the 350 data points that entered this analysis, $7 \%$ were replaced with the mean, and eight subjects were excluded from the analyses (Control-Immediate condition: two; Extinction-Delay condition: three; Extinction-Immediate condition: three). Although mean replacement artificially reduces within-group data variability, thus maximizing between-group differences, we still observed neither an effect of acquisition-extinction interval nor differences among groups in the last block of extinction, $F \mathrm{~s}<1.15$.

During SR testing, the data from six subjects (ControlImmediate-Short and Control-Delayed-Long: one subject each; Extinction-Delayed-Short and Extinction-Immediate-Long: two subjects each) could not be included in the repeated-measures 
analyses. ACondition $\times$ Acquisition-Extinction Interval $\times$ Extinction-Test Interval (short vs. long) $\times$ Block ANOVA conducted on the data collected on the first day of testing revealed main effects of condition and block, $F \mathrm{~s}_{(1,66)}=12.62$ and 46.40, respectively, and a Condition $\times$ Acquisition-Extinction Interval $\times$ ExtinctionTest Interval interaction, $F_{(1,66)}=4.14$. (To simplify the analyses, the two test days were analyzed separately. Including Test Day as a factor revealed the same effects and interaction, as well as a Condition $\times$ Acquisition-Extinction Interval $\times$ Extinction-Test Interval $\times$ Block interaction.) After the short extinction-test interval, extinction was better maintained in the Delayed than the Immediate condition, $F \mathrm{~s}_{(1,66)}=4.75$ and 0.20 , respectively. Conversely, after the long extinction-test interval, extinction was better maintained in the Immediate than the Delayed condition, $F \mathrm{~s}_{(1,66)}=11.03$ and 1.91, respectively. A similar ANOVA conducted on the retest data revealed main effects of Condition and Block, $F \mathrm{~s}_{(1,67)}=16.74$ and 19.60 , respectively. Re-extinction after SR maintained fear suppression in the conditions in which extinction had been effective in the first place (Immediate-Long and Delayed-Short, $F \mathrm{~s}_{(1,67)}=8.13$ and 5.10, respectively), as well as the condition that received Immediate extinction and re-extinction after SR (Immediate-Short, $F_{(1,67)}=4.36$ ). Consistent with the observations of Experiment 1, neither extinction nor re-extinction were effective to attenuate fear in Condition Delayed-Long, $F_{(1,67)}=1.05$.

Extinction is the presumed mechanism underlying exposure therapy in clinical practice (e.g., Craske 1999; Foa 2000), and relapse due to phenomena such as SR can have serious implications for the long-term effectiveness of psychological interventions (e.g., Jacobs and Nadel 1985). The animal studies described above mirror the ongoing debate of whether posttraumatic stress disorder (PTSD) is better addressed with immediate crisis intervention (psychological debriefing) (e.g., Campfield and Hills 2001), or by delaying treatment until the immediate effects of trauma have subsided, which is usual in cognitivebehavioral therapy (CBT) (e.g., McNally et al. 2003). Immediate intervention apparently fails to attenuate the long-term effects of trauma (e.g., Raphael and Wilson 2000), and may even increase the incidence of PTSD (van Emmerik et al. 2002). Conversely, CBT appears to successfully attenuate the effects of trauma in the long term (McNally et al. 2003). Notably, in a psychological debriefing situation, subjects are encouraged to talk about the trauma and its emotional implications, which may not necessarily result in extinction of fear. Because early memories are very susceptible to disruption (e.g., Lin et al. 2003a), reactivating them in conjunction with verbal descriptions of the event may result in reconsolidation of the memory with an added emotional component (e.g., Lee 2008). This memory could become different enough from that of acquisition to result in lowered effectiveness of subsequent extinction treatment.

Our data suggest that the interaction between the acquisition-extinction and extinction-test intervals is one of the determinants of long-term retention of extinction. Possibly, immediate and delayed extinction have different recovery functions. For example, if immediate extinction had a higher recovery rate parameter but a lower recovery asymptote than delayed extinction, SR should occur earlier after immediate than delayed extinction but, after a relatively long retention interval, there should be higher levels of SR in the delayed than the immediate extinction condition. Another possibility is that the acquisition-extinction interval determines the time course of memory recovery after extinction (which can be viewed as a form of retroactive interference) (e.g., Bouton 1993; Miller and Escobar 2002). Immediate testing of potentially interfering memories appears to favor recall of recently acquired information (recency), whereas delayed testing of potentially interfering memories appears to favor recall of remotely acquired information (primacy) (e.g., Wheeler et al. 2004). Short acquisition-extinction intervals may attenuate the "recency-to-primacy shift" usually observed with delayed testing. Whatever the mechanism, our data suggest that immediate extinction-based interventions could provide long-term beneficial effects for fear attenuation and subsequent treatment after relapse, even if delayed interventions appear more beneficial in the short term.

\section{Acknowledgments}

This research was supported by Grant R15 81269 from the National Institute of Mental Health to M.E. We thank Scott Bragan, Laura E. Coursen, Aaron R. Plitt, and W. Travis Suits for their assistance with data collection, and Francisco Arcediano for his comments on an earlier version of this manuscript.

\section{References}

Bouton ME. 1993. Context, time, and memory retrieval in the interference paradigms of Pavlovian learning. Psychol Bull 114: 80-99.

Campfield KM, Hills AM. 2001. Effect of timing of critical incident stress debriefing (CISD) on posttraumatic symptoms. J Trauma Stress 14: 327-340.

Chang C-H, Maren S. 2009. Early extinction after fear conditioning yields a context-independent and short-term suppression of conditioned freezing in rats. Learn Mem 16: 62-68.

Craske MG. 1999. Anxiety disorders: Psychological approaches to theory and treatment. Westview Press, Boulder, CO.

Foa EB. 2000. Psychosocial treatment of posttraumatic stress disorder. J Clin Psychiatry 61: 43-48.

Jacobs WJ, Nadel L. 1985. Stress-induced recovery of fears and phobias. Psychol Rev 92: 512-531.

Lee JL. 2008. Memory reconsolidation mediates the strengthening of memories by additional learning. Nat Neurosci 11: 1264-1266.

Lin C-H, Yeh S-H, Leu T-H, Chang W-C, Wang S-T, Gean P-W. 2003 a Identification of calcineurin as a key signal in the extinction of fear memory. J Neurosci 23: 1574-1579.

Lin C-H, Yeh S-H, Lu H-Y, Gean P-W. 2003b. The similarities and diversities of signal pathways leading to consolidation of conditioning and consolidation of extinction of fear memory. J Neurosci 23: 8310-8317.

Maren S, Chang C-H. 2006. Recent fear is resistant to extinction. Proc Natl Acad Sci 103: 18020-18025.

McNally RJ, Bryant RA, Ehlers A. 2003. Does early psychological intervention promote recovery from posttraumatic stress? Psychol Sci Public Interest 4: 45-79.

Miller RR, Escobar M. 2002. Associative interference between cues and between outcomes presented together and presented apart: An integration. Behav Process 57: 163-185.

Myers KM, Ressler KJ, Davis M. 2006. Different mechanisms of fear extinction dependent on length of time since fear acquisition. Learn Mem 13: 216-223.

Norrholm SD, Vervliet B, Jovanovic T, Boshoven W, Myers KM, Davis M, Rothbaum B, Duncan EJ. 2008. Timing of extinction relative to acquisition: A parametric analysis of fear extinction in humans. Behav Neurosci 122: 1016-1030.

Pavlov IP. 1927. Conditioned reflexes. Oxford University Press, London, UK.

Raphael B, Wilson JP. 2000. Psychological debriefing: Theory, practice and evidence. Cambridge University Press, Cambridge, UK.

Rescorla RA. 2004a. Spontaneous recovery. Learn Mem 11: 501-509.

Rescorla RA. 2004b. Spontaneous recovery varies inversely with the training-extinction interval. Learn Behav 32: 401-408.

Rescorla RA, Wagner AR. 1972. A theory of Pavlovian conditioning: Variations in the effectiveness of reinforcement and non-reinforcement. In Classical conditioning II: Current theory and research (ed. AH Black, WF Prokasy), pp. 64-99. Appleton-Century Crofts, New York.

Schiller D, Cain CK, Curley NG, Schwartz JS, Stern SA, LeDoux JE, Phelps EA. 2008. Evidence for recovery of fear following immediate extinction in rats and humans. Learn Mem 15: 394-402.

Tsao JCI, Craske MG. 2000. Timing of treatment and return of fear: Effects of massed, uniform-, and expanding-spaced exposure schedules. Behav Therapy 31: 479-497.

Urcelay GP, Wheeler DS, Miller RR. 2009. Spacing extinction trials alleviates renewal and spontaneous recovery. Learn Behav 37: 60-73. 
van Emmerik AAP, Kamphuis JH, Hulsbosch AM, Emmelkamp PMG. 2002. Single session debriefing after psychological trauma: A meta-analysis. Lancet 360: 766-771.

Wheeler DS, Stout SC, Miller RR. 2004. Interaction of retention interval with CS-preexposure and extinction treatments: Symmetry with respect to primacy. Learn Behav 32: 335-347.
Woods AM, Bouton ME. 2008. Immediate extinction causes a less durable loss of performance than delayed extinction following either fear or appetitive conditioning. Learn Mem 15: 909-920.

Received July 7, 2010; accepted in revised form September 21, 2010. 


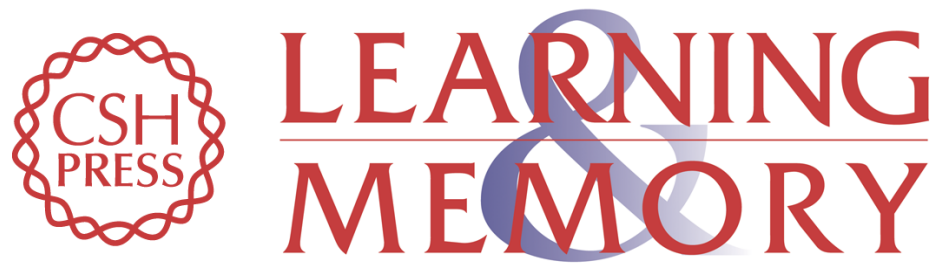

\section{Long-term maintenance of immediate or delayed extinction is determined by the extinction-test interval}

Justin S. Johnson, Martha Escobar and Whitney L. Kimble

Learn. Mem. 2010, 17:

Access the most recent version at doi:10.1101//m.1932310

References This article cites 21 articles, 8 of which can be accessed free at:

http://learnmem.cshlp.org/content/17/12/639.full.html\#ref-list-1

License

Email Alerting Receive free email alerts when new articles cite this article - sign up in the box at the Service top right corner of the article or click here. 